\title{
Leaving the Bench and Finding Your Foundation
}

\author{
John E. Spiro \\ Simons Foundation Autism Research Initiative, Simons Foundation, New York, New York 10010 \\ Correspondence: jspiro@simonsfoundation.org
}

Scientists who leave the laboratory bench to work for biomedical foundations mobilize and focus resources on the most promising research behind a foundation's mission. They acquire a broad view of a field, interact closely with research scientists at meetings and laboratory visits, and often manage proposal review boards and monitor grant progress. Increasingly, scientists at foundations also have a more active role in catalyzing research: They are involved in organizing targeted workshops, setting research priorities, and directly creating and managing resources for a scientific community. They often work closely with patient advocacy groups, contract research organizations, government funders and regulators, and biotech and pharmaceutical companies.

Job opportunities in foundations are highly varied, reflecting the diversity of foundations and missions. For example, some foundations have general missions to support broad basic scientific research, whereas others focus specifically on a particular disease and may require different skills. Most scientific positions at foundations require a $\mathrm{PhD}$ or MD and often some postdoctoral or other experience, although not all do. Foundations often lack the clear career path that an academic position offers (various levels of professorship, tenure, etc.), although there is often significant potential for growth in responsibilities in terms of managing science, people, and budgets. Jobs in foundations can be challenging yet extremely rewarding, especially for those with broad interests and goal-oriented personalities. Many at foundations feel that they have the potential to have an even greater impact than if they had stayed at the bench.

W hat follows is a rather personal account of the state of jobs for bench scientists at foundations. I draw on my own experiences of the last six years, during which time I have worked at a foundation, as well as experience I've gained from talking with numerous friends and colleagues at other foundations; admittedly, my view is rather U.S.-centric. What is clear from even a casual survey is that there is no such thing as an "average" foundation job. Foundations differ enormously in their size, scope, and missions, and likewise, jobs at foundations differ correspondingly.
Several important distinctions stand out and have some bearing on the type of positions that may be available. One is whether the foundation was established with a broad general mission-such as the Rockefeller Foundation, founded in 1913 with a mission "to promote the well-being of humanity" — or rather, whether it was founded with a very specific cause in mind, such as the Michael J. Fox Foundation, launched in 2000 to find a cure for Parkinson's disease. Another major distinction is whether the foundation raises funds from the public to be distributed to research (known as a public

Editors: Kaaren Janssen and Richard Sever

Additional Perspectives on Career Options for Biomedical Scientists available at www.cshperspectives.org

Copyright (C) 2017 Cold Spring Harbor Laboratory Press; all rights reserved; doi: 10.1101/cshperspect.a032904

Cite this article as Cold Spring Harb Perspect Biol 2017;9:a032904 
J.E. Spiro

charity in the U.S.). For many such foundations, money that is raised in a given year is then spent directly on research. Alternatively, other foundations are private and have a single or small number of wealthy donors or a corporate donor-and often, these foundations have a substantial endowment from which operating costs are derived.

Probably the distinction most important to a scientist considering work at a foundation concerns how research is evaluated and supported. A foundation may operate in a more traditional grant-giving mode, primarily making use of outside scientific advisors who are active independent scientists running their own laboratories; alternatively, a foundation may rely heavily on a professional scientific staff and therefore be more proactive in its approach to supporting research. In the former situation, outside advisors evaluate investigator-initiated proposals that come in following a call for applications. The latter more proactive scenario, which is seen increasingly, has created some very interesting and dynamic positions for scientists who leave the bench.

The more proactive model of foundationsespecially for foundations with a disease focusis likely to become more prevalent, leading to an expansion in possibilities for scientists who are interested in employment away from the bench. The main driving force seems to be the recognition that the standard academic (and National Institutes of Health [NIH] or National Science Foundation [NSF] funded) model that works so well for promoting creative research in individual laboratories may not, in fact, be the best model to find cures for various diseases and to put these ideas into practice with patient populations. What is needed in addition (importantly, not instead) is a more focused and targeted approach that often crosses the boundaries of traditional academic research and emphasizes highly collaborative work.

Full-time professional science staff can have a major role in helping to bring about this change. They can work with academic scientists, biotech and pharmaceutical companies, patient advocacy organizations, and others to stay focused on the problem at hand. They need not worry about many of the daily concerns of academic scientists (running a laboratory, getting grants, publishing papers, teaching) and can often very effectively build the infrastructure and teams of experts who can work together to solve complex problems that are difficult or impossible to address in a typical academic setting. Nonprofits that are scientifically nonpartisan can have significant influence in the community given their clear and unencumbered incentives. As such, foundations often have an important role in a research community of helping to set research standards and opening communication channels in various ways. For example, as a condition of a grant award, foundations can require that experiments with negative results be published. Negative results often go unpublished, to the detriment of progress.

The details of this more managed approach depend heavily on the state of knowledge of a given field. As an example, there are still major unknowns about the causes of autism, although it is clear that genetics have a major role. Therefore, the Simons Foundation Autism Research Initiative (SFARI) has made it one of its priorities to assemble a large cohort of families with autism; the families' biospecimens are made available to the basic research community and have been used to help outline the genetic landscape of the disorder. In contrast, in the case of Huntington's disease, the genetics are well established-the gene responsible for Huntington's disease has been known for $\sim 20$ years, but this has not led to effective treatments. The Cure Huntington's Disease Initiative (CHDI) Foundation (http://chdifoundation.org), a private foundation whose focus is on discovering drugs that slow the progression of Huntington's disease, therefore, operates in a space mostly beyond early discovery and is much more focused on making the transition to the clinic, a job that is often reserved for for-profit biotech and pharmaceutical companies. CHDI calls itself a "collaborative enabler." Regardless of the particular focus, foundations-and private foundations in particular, which often lack much of a bureaucracy - can be very nimble compared with other types of funding agencies. As an example, funds can sometimes be mobilized 
extremely quickly if an interesting opportunity arises to the foundation.

For anyone interested in learning more about foundations, I would recommend the Health Research Alliance, a loose organization of many (although by no means all) biomedical foundations. Their website (http:// www.healthra.org/) can serve as a launching pad for finding out more about various foundations. Another organization, GuideStar (http://www.guidestar.org/), provides a rich data set on nonprofits. One service is to potential donors, who can use GuideStar to evaluate whether a particular nonprofit operates efficiently. But prospective employees can benefit greatly as well, because the site provides detailed information gathered from tax returns and other sources that get right to the bottom line about foundations: how much money they have and where they spend it. GuideStar presents this information without obscuring the details, as is often the case on some foundation websites.

\section{JOBS AND CAREER PROGRESSION}

Jobs for scientists at foundations vary significantly depending on the size and style of the foundation, as described above.

For foundations that primarily put out requests for applications in a focused area and review grants that come in-and rely heavily on an external board of professional scientists who review and advise - a common job title that reflects the responsibilities is "program officer." A program officer may be responsible for grants in a particular area and his/her job will largely entail writing requests for applications, helping to manage scientific review boards, monitoring progress on grants-including site visits - and dealing with principal investigator (PI) requests to change scope or budget. With increasing experience and independence, the position might entail a promotion to senior program officer.

For the more proactive foundations described above, much more weight is placed on the internal foundation scientists to evaluate, coordinate, and drive the research. Responsibilities might include launching and managing infrastructure projects, organizing targeted workshops, and evaluating grants and other projects in-house, with additional external advice taken ad hoc. In addition to giving grants, where the external PI is expected to construct and perform a research project, responsibilities of a scientist in such a foundation might include more general overview and supervision. For example, the foundation scientist would be involved in the initial phase of setting the project goal(s) and design, followed by a phase in which the work is done by an academic laboratory or contract research organization, or in some consortium arrangement that is often best described as a contract as opposed to a grant. Scientists at foundations that raise money are often involved in fundraising efforts in some way.

Titles at foundations tend to follow an NIH model (program officer, senior program officer) or a model that is familiar to academics such as assistant, associate, and senior and deputy director for research, leading up to scientific director. Alternatively, some foundations use a model that is more familiar to those in the corporate world, such as vice president (VP) for research, senior VP, chief research officer, chief scientific officer, executive director, etc.

Careers at foundations often lack the established structure/hierarchy found at universities (including tenure!). Nevertheless, despite the different types of titles, promotion at a foundation usually brings increased independence in decision making and often involves additional expectation of initiative and leadership. More senior personnel are expected to be able to represent the organization externally and to participate actively in strategic planning, goal setting, hiring, and management of staff and budgets. At some foundations (but certainly not all), the highest scientific position is often reserved for individuals who have had a distinguished career in academia (perhaps as a department chair or similar) who then decided to make a transition to a foundation at a later career stage. So, for some of the most senior positions, having run a laboratory (maybe even a big one) is something of a prerequisite.

Data on the number of jobs for scientists in foundations is hard to come by, but anecdotally the number of positions is on the rise. This is 
J.E. Spiro

likely the result of a complex combination of limited federal funding for research and an increasing awareness of the important role for advocacy organizations to help provide, focus, and direct research spending. The rise is also likely tied to the rise of wealthy donors and favorable tax laws for foundations in the United States. Finally, foundations tend to be nice places to work, with competitive salaries and good benefits.

\section{SKILLS AND QUALIFICATIONS}

Not surprisingly, the skills required differ significantly based on a foundation's mission. On balance, however, a scientist at a foundation is expected to interact with the scientific community at a high level and will make decisions that can have a significant impact on a field, and thus is expected to have a $\mathrm{PhD}$ or an MD. Given the current job market and the relative plethora of scientists with postdoc experience who are looking for jobs, it is advantageous for someone to have completed a postdoc. This is not necessarily about the additional scientific training that one might get as a postdoc (although that is always good), but as much so about more life and job experience - and experience in a setting different from one's $\mathrm{PhD}$ laboratory.

In general, prospective foundation employees should be able to think comprehensivelyand optimistically_about scientific problems while maintaining attention to detail. It is not uncommon to have to deliver difficult news to prospective grantees, so resilience in making tough calls is essential. Scientific research is inherently uncertain and involves many failures. An optimistic attitude is therefore essential, especially as foundations often position themselves as greater risk takers compared with traditional funding bodies - and thus often deal with failed experiments.

The jobs almost always involve communicating with a large number of scientists with very different backgrounds and personalitiesand also working with different types of internal teams - so strong interpersonal and written/ oral communication skills are very important. At foundations that raise money, the job may involve speaking with existing or potential donors, and skill in talking about science comfortably at multiple levels would be relevant. Regardless of the type of foundation, it is almost certain that the job will involve thinking more broadly about scientific questions than when one is at the bench, so a passion for learning new material is essential. Related is a willingness to travel to meetings and make laboratory visits.

Beyond these rather general statements, skills required may be specific to a given foundation. For example, for a foundation that centers on issues that primarily revolve around neuroscience, it would be highly advantageous to have training in that field. Similarly, for a foundation that operates in a space that is very advanced clinically and involves drug trials, for example, experience in a biotech or pharmaceutical company may be a prerequisite.

One active debate among those of us who have responsibility for hiring new science staff has to do with the skills that are prerequisite and those that can be learned on the job. Interpersonal and communication skills and a genuine curiosity and passion for science are essential, as is being comfortable dealing with uncertainty and a rapidly evolving knowledge base. More specific skills, such as knowledge of the best methods for managing review boards and dealing with grant management, can generally be learned on the job.

\section{GETTING A FOOT IN THE DOOR}

There is no set formula for getting your foot in the door for any foundation, but there are a few general strategies that can help.

Do not hesitate to send an email to scientists at a foundation that you admire. Perhaps you know about a foundation because it supports work in a field in which you have worked or are otherwise interested in, or perhaps you have some more direct connection to the mission of a foundation given a family member with a particular illness. Another approach is to check out the acknowledgment sections of scientific papers that you admire, or look for who supports interesting work as you browse posters at a scientific meeting. 


\section{BOX 1. My Experience}

As a result of a very engaging mentor, I was hooked on biology, and on neuroscience in particular, as an undergraduate at Haverford College. I got my PhD at University of California, San Diego (UCSD) in the laboratory of the late Walter Heiligenberg. I then did postdoctoral work in the department of neurobiology at Duke University Medical Center in the laboratory of Richard Mooney. For both my PhD and postdoctoral work, I used multiple types of techniques ( primarily electrophysiology, anatomy) to try to understand the neural basis of behavior. I enjoyed and was deeply intellectually engaged in the work that I was doing. This is probably most clearly reflected in the fact that I spent much of my time outside of the laboratory on mountain biking, hiking, or sailing trips talking about biology and neuroscience with friends, whom my teenage daughters now lovingly refer to as my "nerd friends."

At both UCSD and Duke, I was privileged to have been surrounded by an enormous variety of science. At UCSD in particular, to where scientists flocked from everywhere in the world (especially in wintertime when it was warm and sunny in La Jolla), I was very distracted by the huge assortment of excellent seminars that were available each week. With UCSD, Scripps Oceanography, the Neuroscience Institute (now closed), the Salk Institute, and Scripps Clinic, La Jolla was a science mecca.

In the back of my mind, I always harbored some doubt that I was going to thrive in an academic atmosphere. I felt that I would be forced to become a superspecialist in one particular area, which is the standard practice for someone who pursues an academic career and must make a name for oneself to get tenure. Science generalists are not usually rewarded unless they move to a position where the primary responsibilities involve teaching.

Despite these reservations, I started to apply for faculty jobs several years into my postdoc at Duke. At the same time, Nature Neuroscience, a new neuroscience spinoff from the weekly Nature, was just turning one year old, and the launch editor/editor in chief, Charles Jennings, was visiting Duke to get feedback about the journal. I attended a lunch with several other postdocs, and I was struck by how Jennings described the intellectual atmosphere at the journal. In essence, one could get paid to be a generalist in neuroscience. As a postdoc, I was also working very long hours. I was doing electrophysiology experiments that often went late into the night. With two young children and a wife who worked, it was difficult to balance. At one point, describing what I did at work to a family friend, my three-year-old daughter said that an experiment was "when Daddy doesn't come home for dinner." Working at Nature Neuroscience was very hard work but had more controllable hours.

I applied for a position as an assistant editor, and when I was offered the job, spent several weeks thinking deeply about leaving the laboratory. I convinced myself that I could do it for a year or two without burning any bridges to a more traditional academic path.

Fortunately, I thoroughly enjoyed the work and had excellent colleagues. I started handling manuscripts in circuits/systems neuroscience that I knew well and gradually expanded into other areas by traveling around the world to all sorts of meetings and making laboratory visits. I especially enjoyed getting to see the different types of cultures that defined different communities within neuroscience-and relished the access to top-notch scientists/advisors that comes with this type of position. It was truly eye opening to realize that two eminent referees could completely disagree about the importance of a particular piece of work.

I eventually worked my way through associate and senior editor at Nature Neuroscience, and then moved over to Nature, where I eventually became a senior editor on the biology team, where my responsibilities included all of neuroscience and where I oversaw a small team of other editors in neuroscience. Nature presented some additional opportunities as I interacted with editors in other disciplines of biology and the physical sciences, including the "front half" "News and Views" editors and various news writers and editors. It was also a time where there were major challenges (mostly driven by the web and open access) to the traditional models of publishing.

One of the main reasons for leaving the laboratory was to be able to remain a science generalist. After being at Nature Publishing Group for more than seven years and handling manuscripts and

(Continued) 
J.E. Spiro

interacting with many different types of communities, I started to look around for an opportunity where I could dig a bit deeper. I was attracted by the idea of sticking with a topic for a longer period of time compared with the length of time it took for a manuscript to make it through review and publication. By taking the lead on various special focus issues at Nature, I developed some taste for this and I enjoyed it.

The Simons Foundation was starting an initiative to understand autism (SFARI). I was attracted to this opportunity because it was/is clear that to make progress in understanding autism spectrum disorder (ASD) one needs to make connections between the genetics, neural circuits and systems, and behavior. There were also multiple challenges inherent in coming up with constructive ways to engage and keep the research community focused on SFARI's mission and research priorities, especially in the realm of translating basic research findings into possible avenues for treatment. SFARI has given me an opportunity to stay broad in my thinking but to also dig deeply into particular issues and be involved in all stages of research, not just at the stage of a finished manuscript.

\section{BOX 2. Ten Dos and Don'ts}

1. Do not assume that a PhD is about technical training. On the contrary, it is about learning how to make sense of a huge and rapidly evolving body of specific knowledge while keeping a broad view and about learning how to communicate clearly. These are highly transferable skills.

2. Do not worry about those who think you are "dropping out of science" or disappointing former mentors by not pursuing a traditional academic career.

3. Do realize that you can have a significant impact on a field even though you are not at the bench. Sometimes, even more so.

4. Do realize that although you may have an important role in research, you will likely need to be comfortable being part of a team and not necessarily the center of attention. In employment ads that I have seen, I think the phrase "low ego needs" sums it up well.

5. Do try to expand your horizons while you are at the bench by writing and reading broadly beyond your area of expertise in the laboratory.

6. Do be sure that you are comfortable with the inevitable trade-off of breadth versus depth that comes with leaving the bench. You will no longer likely be the "world's expert" in a particular subfield, but you will probably be exposed to a much larger community of scientists than if you had stayed at the bench.

7. Do write/call scientists working at foundations that may be involved in supporting the work that goes on in your laboratory.

8. Do research on foundations that you are interested in; know their mission, know where the money comes from.

9. Do research the people who work at foundations that interest you. (Use various web resources, such as GuideStar.)

10. Do practice talking to scientists who work in different disciplines. Try to understand their language and their community and practice explaining your science and community to them. 
It is important to be able to demonstrate that you can function in a situation beyond the bench. This may involve having evidence that you can be passionate about and can communicate scientific ideas that go beyond your immediate technical expertise. One way to get this type of experience is to write for a university publication or a website or other forum that seems appropriate. If you have a particular foundation in mind, offer to write for their website if they have one. Propose ideas for a workshop and/or offer to help organize it. Foundations often advertise jobs on their websites and in the job sections of various general science journals.

\section{WAY OUT}

Leaving the laboratory and a "traditional" academic career is a big career move. After being out of the laboratory for a year or two, it can be difficult to get back into laboratory research that you may have been doing, seeing as science most likely will have progressed significantly. That said, if one were to take a job as a scientist at a foundation, an ecosystem of related jobs are possible if the specifics of the job at a foundation are not working out. For example, there is substantial movement between jobs at other foundations or related jobs such as a program officer at a big government funder such as the $\mathrm{NIH}$, editor at a scientific journal, university administrator, staff member at a biotech company, or as an independent consultant.

\section{ACKNOWLEDGMENTS}

I thank Dr. Brian Fiske for comments on an earlier version of this chapter.

\section{WWW RESOURCES}

http://www.healthra.org Health Research Alliance. http://www.guidestar.org GuideStar. 


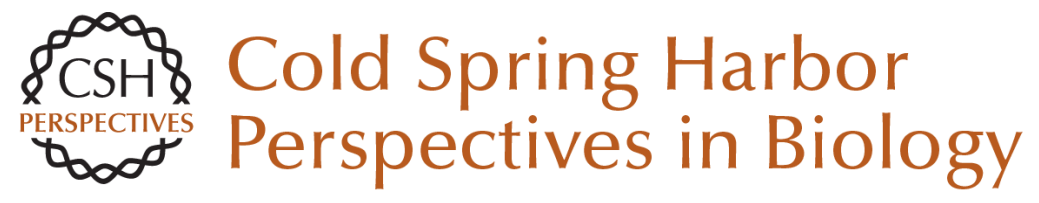

\section{Leaving the Bench and Finding Your Foundation}

John E. Spiro

Cold Spring Harb Perspect Biol 2017; doi: 10.1101/cshperspect.a032904

Subject Collection Career Options for Biomedical Scientists

\section{Careers in Science Publishing} John R. Inglis

Medical Communications: The "Write" Career

Path for You? Yfke Hager

At the Crossroads of Science and Society: Careers in Science Policy Amy P. Patterson, Mary E. Groesch, Allan C. Shipp, et al.

A Career in Patent Law: At the Cutting Edge of Science, but Not at the Bench Salim Mamajiwalla

Careers in Science and Grant Administration: View from the National Institutes of Health Marion Zatz and Sherry Dupere

Careers at Biotech Start-Ups and in

Entrepreneurship Susan Froshauer

Careers in Science Journalism and Writing Helen Pearson

\author{
Careers in Academic Administration \\ Lydia Villa-Komaroff \\ Working for a Scientific Society \\ Martin Frank
A Career for Life Scientists in Management Consulting Rodney W. Zemmel \\ Careers in Core Facility Management \\ Claire M. Brown \\ Leaving the Bench and Finding Your Foundation \\ John E. Spiro
A Career at a Small Liberal Arts College Jennifer Punt \\ Career Options for Scientists \\ Richard Sever and Kaaren Janssen
}

For additional articles in this collection, see http://cshperspectives.cshlp.org/cgi/collection/

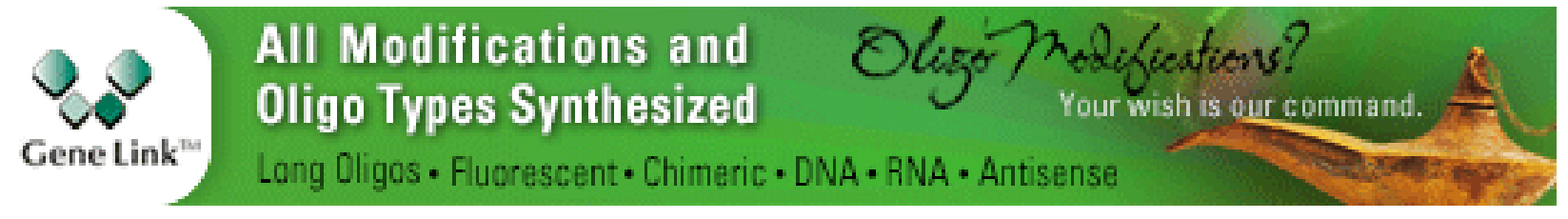

Copyright @ 2017 Cold Spring Harbor Laboratory Press; all rights reserved 